UNDERGRADUATE DISCOVERY

FELLOWSHIPS IN

\title{
SPECIAL COLLECTIONS
}

Author:

Neil Weijer

Curator of the Rare Book Collection

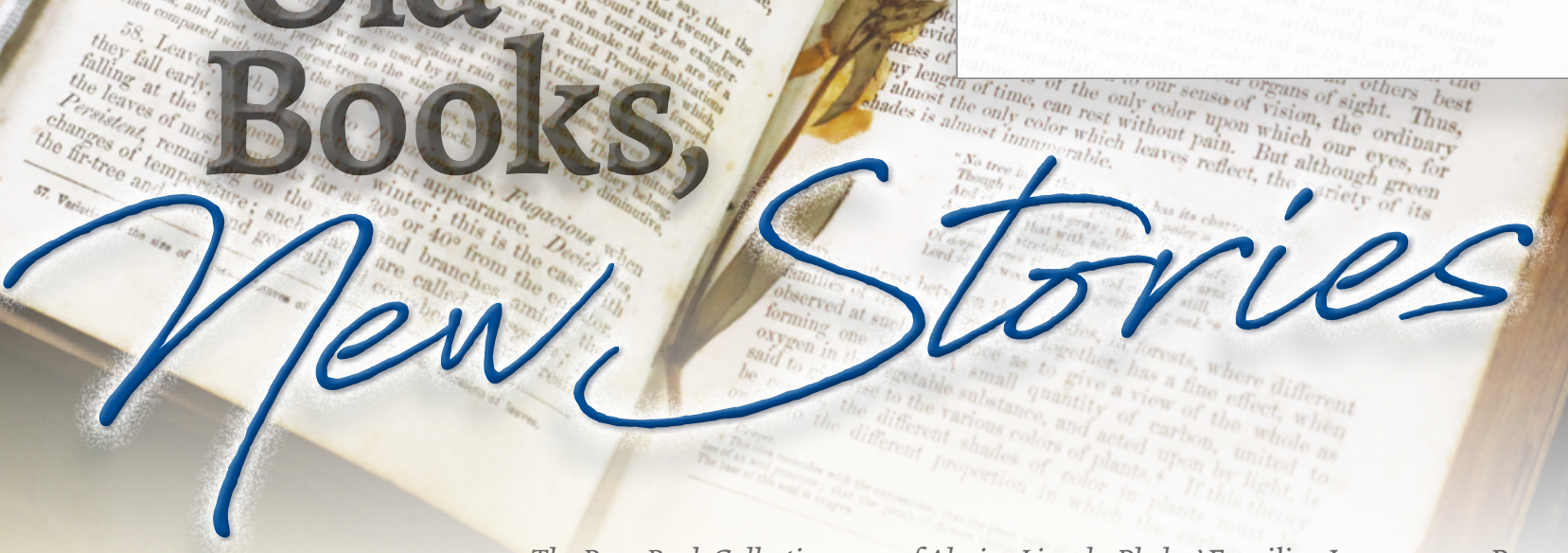

The Rare Book Collection copy of Almira Lincoln Phelps' Familiar Lectures on Botany (1852) contains two students' inscriptions and flowers pressed between its pages.

I still remember the first time I went into a special collections library on my own. I was a third-year undergraduate, and a professor had told me about two medieval English manuscripts in our library and suggested I look at them for thesis ideas. I nodded calmly as I heard these words, but inside I was thinking, "I can do that? Show them my student ID and they'll let me use a 500-year-old book?" Turns out, yes, but it took the patience and help of librarians and graduate advisors for me to learn how to use the manuscripts properly, let alone read their archaic spelling and crabbed handwriting. Without those experiences, I wouldn't be where I am now, but to many undergraduates, special collections are less a door waiting to be opened than a room hidden behind a false bookcase-there only for people who know where, and how, to look.

When I came to UF, I wanted to create ways for students to feel comfortable using the Rare Book Collection for their own research and creative work. This spring, with the generous support of Joseph and Rebecca White, Special \& Area Studies Collections hosted the first cohort of three Undergraduate Discovery Fellows. Under the (virtual) mentorship of myself and Bridget Bihm-Manuel, Florida History Coordinator, these fellows dove into the collections, pursuing individual questions that they wanted to explore.

Our fellows came from different departments and different stages of their undergraduate careers, but they applied with a topic and a question that they wanted to explore. Our job as mentors was to help their questions evolve over the course of the semester. By the end of April, our fellows had looked through materials from four of our print and archival collections in SASC. They were each asked to frame their question in a blog post in the middle of the semester, and come up with a final project that reflected on what they'd seen in the Library and their process of discovery.

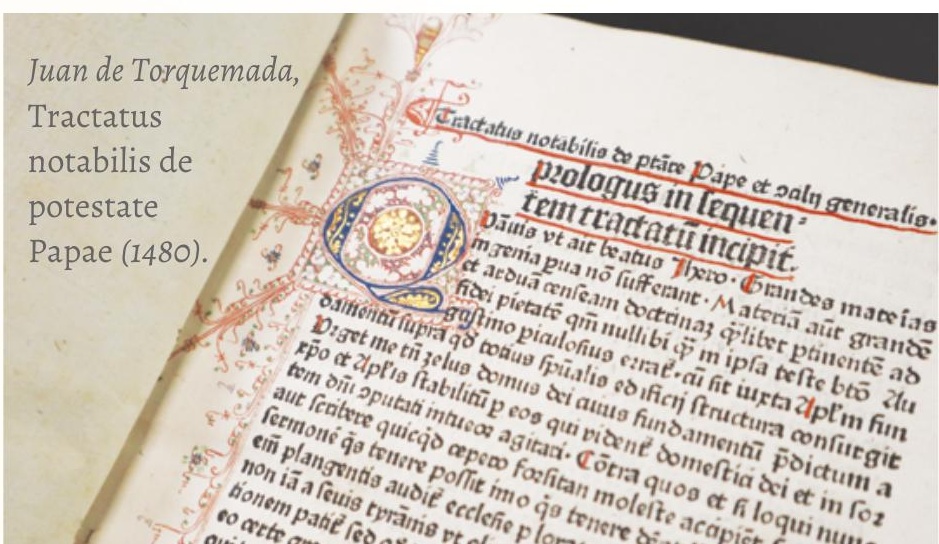




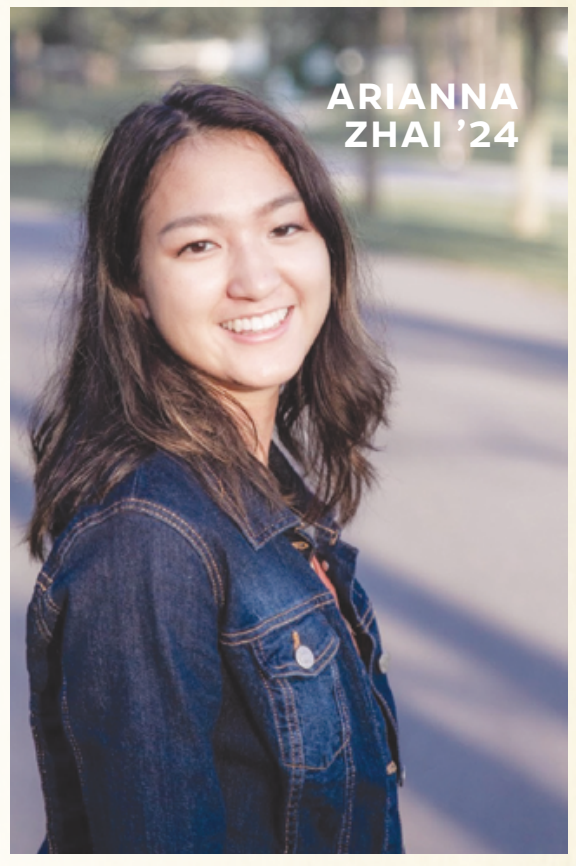

For Arianna Zhai ('24), that question came

from the arena of public health and medicine and her own love of "self-help" books: how did professionals and the general public define the idea of "health" in earlier periods. Zhai's project looked at collections of remedies, recipes, and books written by practitioners from the 1780 s to the 1950 s. Almanacs and medical manuals provided a look into how health, or healthfulness could be described, sought after, and even patented and sold. At the same time, popular physicians like John Harvey Kellogg were arguing that modern fashions were as damaging to women as society's conditioning of girls to play with dolls and tea sets as infants. Arianna's work in the areas of public health and medicine are just getting started, and the fellowship has given her a path to continue looking at how specialists try to convince people that certain things are good for them.

\section{"WHILE GOOD GENERAL PUBLIC KNOWLEDGE CAN SPREAD WIDELY, THE SAME IS TRUE ABOUT INEFFECTIVE MEDICAL REMEDIES." -ZHAI}

A selection of almanacs from the Rare Book Collection (1788-1953). Each of these pamphlets advertised a combination of astrological, medical, and informative cures for readers, and was made to be displayed in prominent places.

John Harvey Kellogg's Ladies' Guide in Health and Disease (1893). As director of the Battle Creek Sanitarium and the author a series of "modern" medical treatises, Kellogg was one of the most prominent national voices on personal health and wellness in the early twentieth century.
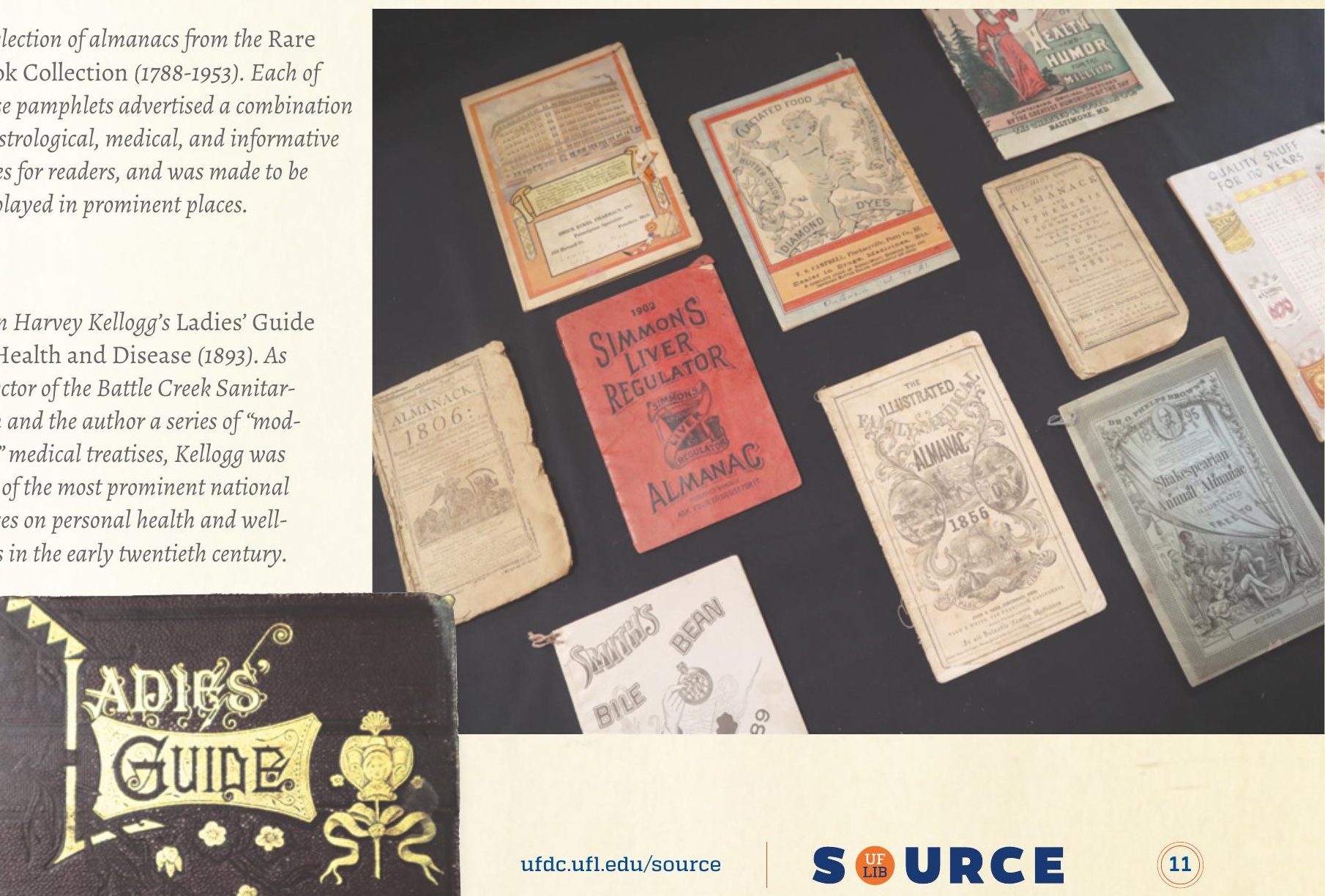


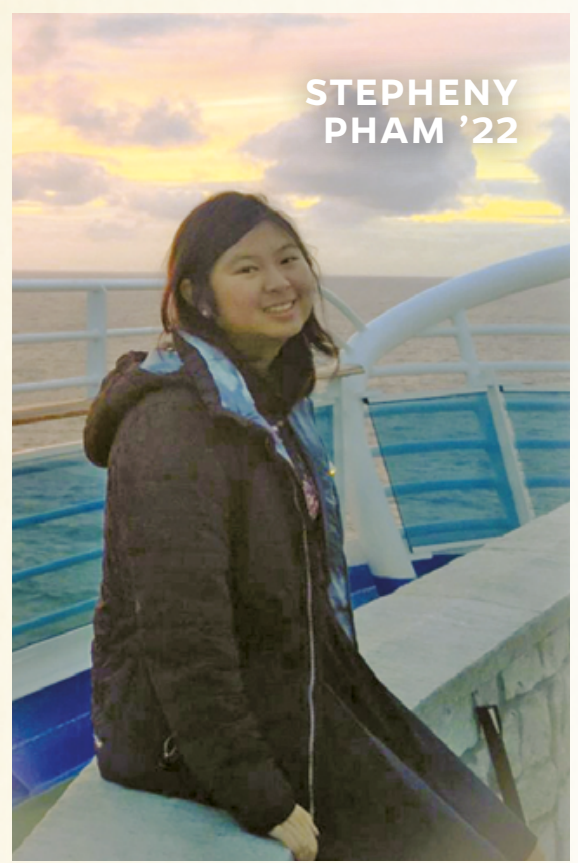

Stepheny Pham ('22) drew on her experience as a Zoology major and Asian Studies minor to search for ways that animals, wild and domestic, took on different cultural meanings across time and place. She looked through husbandry manuals, ornithology books, and other ephemera, and found a focus in Kono Bairei (1844-1895), a master of Kacho-e, or "bird and flower art." Bairei's art was widely known both in Japan and in the West due to its distribution in books and exhibition at events like the Chicago World's Fair. Both the ways he depicted animals and the ways that his books were made was quite different than European natural histories of the time. Her final reflections included a collage of some of the woodblock illustrations found in the six volumes of Bairei's Book of 100 Birds, printed between 1881 and 1884 .

\section{"IT WAS FUN AND FASCINATING TO READ ABOUT THESE TOPICS AND UNCOVER THE RICH HISTORIES BEHIND EACH IMAGE." - PHAM}

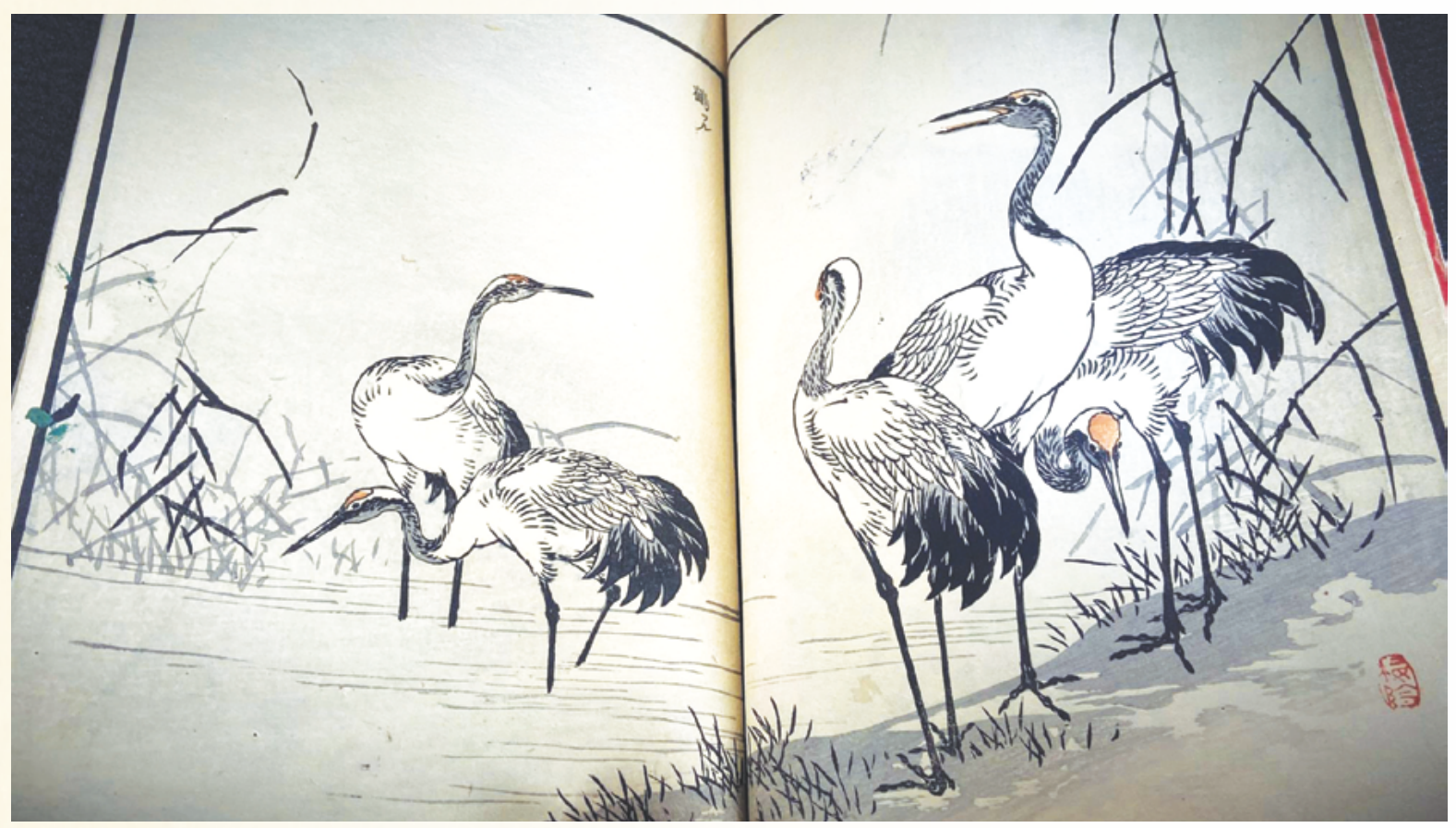

Red-crowned cranes, from Kono Bairei's Book of 100 birds (1881). Credit: Stepheny Pham

MORE INFORMATION ABOUT THE DISCOVERY FELLOWSHIPS AND THE FELLOWS' RESEARCH PROJECTS CAN BE FOUND ON THE STORIED BOOKS PROJECT'S WEBSITE: 


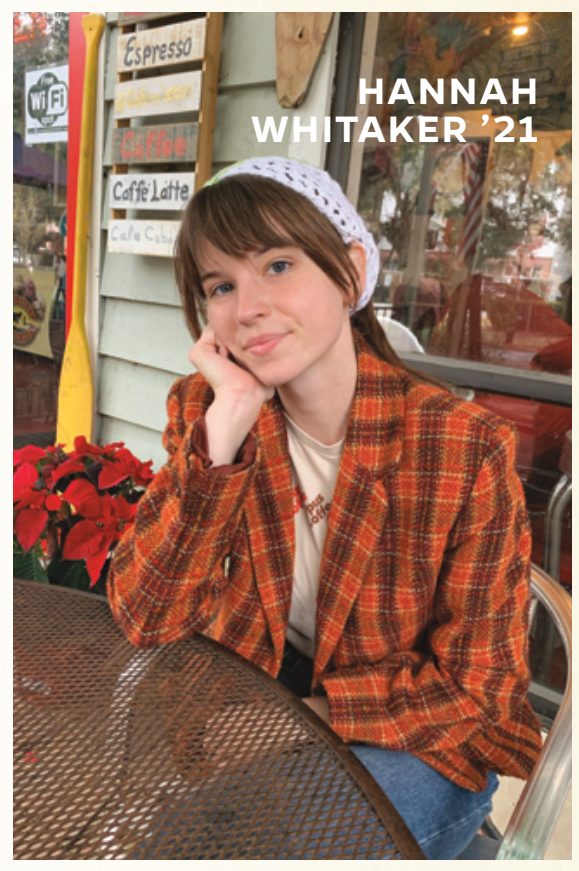

Finally, Hannah Whitaker ('21) came in with a question about the circulation of Victorian literature, and came out in a very different place: female environmental writers. Her journeys through the collections brought her to a group of nineteenth-century women who created textbooks and stories to teach science and respect for the natural world to children, especially girls. Books like the Look About Club (1887) were equal part fact and fantasy, as children were taught about nature by animals themselves. Her online display highlights another discovery of local interest: a copy of an early American botany textbook with flower pressings and the inscriptions of two young female readers-one in Alabama and one in Gainesville. Hannah is now

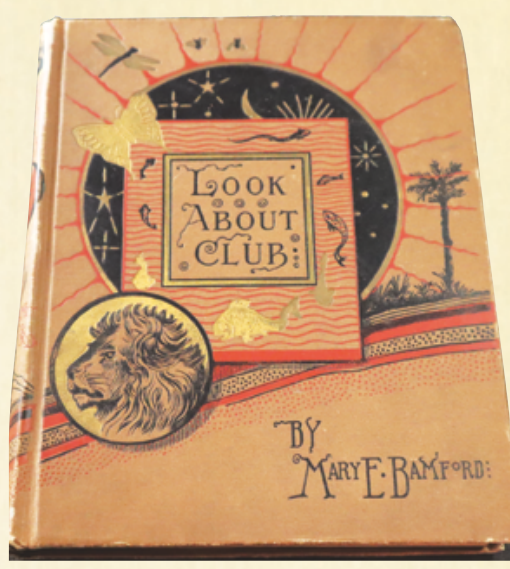

Mary Ellen Bamford, Look About Club (1887) applying to library programs and looking to turn more of her research into writing for the public.

\section{“I MET AMAZING PEOPLE AND DECIDED THAT THEIR CAREER WAS WHAT I WANTED TO PURSUE." -WHITAKER}

Hannah Whitaker's Scalar display, "Women and Stems" can be seen on the Storied Books Scalar page:

http://storiedbooks.domains.uflib.ufl. edu/Scalar/women-and-stems/index

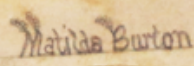

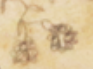

Suntervile Female Academy

Ara.

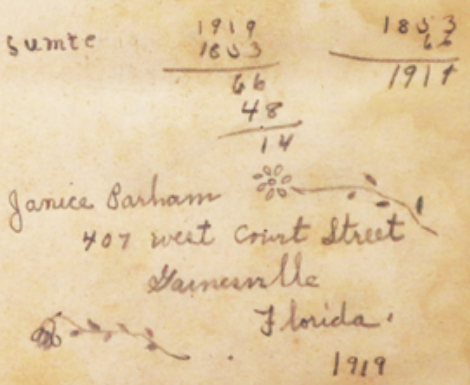

Janice

Inscriptions of Matilda Burton and Janice Burham on the front flyleaves of Almira Lincoln Phelps' Familiar Lectures on Botany (1852).
As with many things, the pandemic changed the way that we had envisioned the program, but in some ways made for a stronger group. In the middle and end of the semester, we decided to check in (outside) over coffee as a group so we could see each other outside of our Zoom boxes. The fellows shared discoveries found in their materials and their ideas for projects, and these conversations helped them a sense of togetherness that would have been hard to come by as individual researchers. These meetings will be a feature of the fellowship going forward.

Thanks to dedicated faculty and librarian instructors and digitization efforts, special collections have become much more accessible in recent years. Calling them approachable is still a stretch. There are limitless possibilities in the stacks of Smathers Library, but in order to realize them students have to be able to see themselves in the materials. The Discovery Fellowships are a way for interested students to learn how to look, to experiment, and to create in the collections, without the pressure of having a paper due at the end of the semester.

The work done through the Discovery Fellowships will feature on the project site Storied Books at the University of Florida, and will give future cohorts of researchers space to bring their ideas and voices to the collections: their very own Look-About Club.(S) 